http://jmscr.igmpublication.org/home/ ISSN (e)-2347-176x ISSN (p) 2455-0450 crossref DOI: https://dx.doi.org/10.18535/jmscr/v8i1.35

Original Research Article

\title{
Prevalence of pulmonary manifestations in connective tissue disorders (Systemic Lupus Erythematosus, Rheumatoid Arthritis, Systemic Sclerosis)
}

\author{
Authors \\ Soumya Sarathi Mondal ${ }^{1}$, Ankan Saha $^{2^{*}}$, Sanjay Kumar Mandal ${ }^{3}$, Koelina Sil ${ }^{4}$ \\ ${ }^{1}$ Associate Professor, ${ }^{2}$ Junior Resident, ${ }^{3}$ Professor, ${ }^{4}$ Assistant Professor \\ Department of Medicine, Medical College and Hospital, Kolkata
}

*Corresponding Author

Dr Ankan Saha

Junior Resident, Department of Medicine, Medical College and Hospital, Kolkata, India

\begin{abstract}
Introduction: Connective tissue diseases comprises several immunologic systemic disorders. The pleuropulmonary manifestations frequently occur in these patients. So the identification of the respiratory manifestations is a major concern.

Aim: To find out the prevalence of different respiratory manifestations in most common connective tissue disorders (systemic lupus erythematosus, Rheumatoid arthritis, Systemic sclerosis).

Methodology: A Hospital based cross-sectional, observational study conducted on 50 diagnosed cases of connective tissue diseases, of which 33 are SLE, 10 RA and 7 SSc. All these patients underwent clinical evaluation and Spirometry, Chest x-ray, HRCT scan of thorax and Echocardiography.

Results: Mean age of presentation was 32.9 and female: male 44:6. Spirometry showed restrictive change in $74 \%$ of total patients (72\% of SLE, $70 \%$ of RA and $86 \%$ of SSc patients). From radiological point of view $38 \%$ of total patients had interstitial lung disease (20\% of RA, 36\% of SLE and $72 \%$ of SSc patients had HRCT findings suggestive of parenchymal lung diseases) followed by pleural effusion -10\% of total patients (20\%,6\% and 40\% patients of RA, SLE and SSc respectively). $28 \%$ of all the patients had mild pulmonary hypertension (20\% of RA, $21 \%$ of SLE and 57\% of SSc patients).

Conclusion: Regarding respiratory system, most of the patients in our study develop restrictive type of lung disease. Pulmonary hypertension occurs in patients with connective tissue diseases but not very common. Diffuse parenchymal lung disease, pleural effusions are dominant pleuropulmonary manifestations in our study.

Keyword: SLE, SSc, RA, Restrictive Lung Disease, ILD, Pulmonary Hypertension.
\end{abstract}

\section{Introduction}

The term "connective tissue disease" (CTD) is defined as a heterogeneous group of disorders, some hereditary, others acquired, characterized by abnormal structure or function of one or more of the components of connective tissue, i.e., collagen, elastin, (and cells) or the mucopolysaccharides. But most Commonly this term is limited to a group of autoimmune disorders that are classified among the systemic rheumatic diseases and include rheumatoid arthritis (RA), systemic lupus erythematosus (SLE), systemic sclerosis (SSc), polymyositisdermatomyositis (PM-DM), primary Sjögren's 
syndrome (SS), primary antiphospholipid syndrome (APS), and mixed connective tissue disease (MCTD) ${ }^{[1]}$. Among the above mentioned CTDs RA, SLE and SSc are more frequently found all over the world as well as in India. The pulmonary manifestations are common in patients with connective tissue disorders (CTDs). All the elements of the respiratory system are affected. This includes the respiratory muscles, the pleura, and the lung parenchyma - the small airways, the interstitium, or the pulmonary vessels.

The frequency and type of lung involvement in connective tissue disorders varies based on the underlying disease. Although most of the pulmonary complications appear after some time of diagnosis of CTDs, in some situations, the lung disease may precede the more typical manifestations of the underlying disease. Pleuropulmonary manifestations of SLE are diverse and can involve any aspect of the lung. Pleuritis will develop in as many as $50 \%$ of patients with SLE. Clinically apparent pleural effusions are typically small, bilateral, and exudative. ${ }^{[2]}$ Acute lupus pneumonitis is a rare manifestation of SLE that presents as a severe, acute respiratory illness with fever, cough, pulmonary infiltrates, and hypoxemia.

Chronic interstitial lung disease is a rare manifestation of SLE. It occurs more commonly in other connective tissue diseases such as systemic sclerosis, RA, and polymyositis/ dermatomyositis. Interstitial lung disease in the setting of SLE can develop after one or more episodes of acute pneumonitis but can also occur in an insidious fashion. ${ }^{[3]}$ Pulmonary involvement in RA is relatively common, with targets including the pleural or parenchyma tissue. Pneumonitis and fibrosis are perhaps the most common and serious forms of pulmonary involvement in RA. On average, patients with RA complicated by ILD experience a 7-year reduction in median survival compared with patients with RA without lung disease. ${ }^{[4]}$

Pulmonary involvement is found in most patients with scleroderma. ILD and pulmonary hypertension are recognized as the most common lung complications and are now regarded as the major cause of death in scleroderma. In combination, it is estimated that they are responsible for $60 \%$ of scleroderma-related deaths. ${ }^{[5]}$ They are present in many patients at the same time, but one process may dominate over the other. The pulmonary manifestations of RA are varied, the most common being pleural abnormalities and ILD, while in scleroderma, the interstitial fibrosis and pulmonary hypertension are the most common pulmonary manifestations. There are very few Indian studies documenting respiratory involvement in CTDs.

Hence, the present study was undertaken to evaluate the various pleuro-pulmonary manifestations in various CTDs.

\section{Methodology}

The present study is a hospital based cross sectional, observational study conducted at Medical College and Hospital, Kolkata from January 2018 to July 2019. Total 50 patients who were diagnosed to be suffering from any of the most common three connective tissue diseases SLE, RA and SSc, by relevant clinical and biochemical tests, are selected from patients attending Medicine and Rheumatology outpatient department. All proven cases of SLE, RA and SSc are included in the study. Patients suffering from chronic airways obstruction, upper airway diseases, left ventricular failure or any cardiac diseases, lung cancer, occupational lung diseases and other forms of interstitial lung diseases are excluded from the study. After meeting the inclusion and exclusion criteria and consents being taken from the patients, the following tests done for the diagnosis of the pulmonary manifestations in these cases: haemogram and serum biochemistry, chest radiograph, pulmonary function testing, high resolution computed tomography (HRCT) of thorax, echocardiography. The HRCT of thorax could not be done in some cases due to the financial constraints. The forced expiratory volume in the first second (FEV1), 
forced vital capacity (FVC), FEV1/FVC and forced expiratory flow between $25 \%$ and $75 \%$ of vital capacity (FEF 25-75\%) are taken into consideration for analysis. All the parameters less than $80 \%$ of the predicted are considered to be reduced. Diffusion capacity of the lung for carbon monoxide was not tested as the facilities are not available at our hospital. In the absence of dynamic compliance and closing volume estimation, FEF25-75\% is considered to be a marker of smaller airway function.

All patients are observed over a period of one year with clinical evaluation and pulmonary function testing.

\section{Results}

Basic characteristics of the patients are given in table 1 and 2. Out of all the patients majority of patients are having SLE (33 in number, 66\%), followed by patients having RA (10 in number, $20 \%$ ) and then SSc (7 in number, 14\%). In our study patients age ranged from 16 to 56 years, which were divided into five groups. In our study most of the patients were in the age group of 21 to 30 , around $38 \%$ patients belonged to this age group followed by 15 patients (30\%) in age group of 31 to 40 years. Mean age being 32.9 years. We analyzed the sex distribution of our study group where we observed that majority of the patients belong to female (total 44 patients, $88 \%$ ), where as male patients are only of $12 \%$. We also analyzed the sex distribution of patients according to different diseases and that $88 \%$ of all SLE patients, $90 \%$ of all RA patients and $86 \%$ of all SSc patients were female and rest were male. It was observed that connective tissue diseases are more common in females than males.

Table 1- Demographic characteristics (sex) of the patients

\begin{tabular}{|l|c|c|c|c|}
\hline DISEASE & $\begin{array}{c}\text { Total } \\
\text { patients }\end{array}$ & Percent & Male & Female \\
\hline RA & 10 & $20.0 \%$ & 1 & 9 \\
\hline SLE & 33 & $66.0 \%$ & 4 & 29 \\
\hline SSc & 7 & $14.0 \%$ & 1 & 6 \\
\hline Total & 50 & $100.0 \%$ & 6 & 44 \\
\hline
\end{tabular}

SLE- Systemic Lupus Erythematosus; RA- Rheumatoid Arthritis; SSc- Systemic Sclerosis
Table 2- Age distribution of the patients studied

\begin{tabular}{|l|c|c|c|c|}
\hline Age in Years & Total patients & SLE & RA & SSc \\
\hline $\mathbf{1 6 - 2 0}$ & 5 & 3 & 2 & 0 \\
\hline $\mathbf{2 1 - 3 0}$ & 19 & 14 & 2 & 3 \\
\hline $\mathbf{3 1 - 4 0}$ & 15 & 6 & 5 & 4 \\
\hline $\mathbf{4 1 - 5 0}$ & 7 & 6 & 1 & 0 \\
\hline$>\mathbf{5 0}$ & 4 & 4 & 0 & 0 \\
\hline Total & 50 & 33 & 10 & 7 \\
\hline
\end{tabular}

SLE- Systemic Lupus Erythematosus; RA- Rheumatoid Arthritis; SSc- Systemic Sclerosis

$28 \%$ of all the patients were having pulmonary hypertension. Majority of them around $72 \%$ did not have any pulmonary hypertension. $20 \%$ of all RA patients had pulmonary hypertension, $21 \%$ of all SLE patients had pulmonary hypertension and $57 \%$ of all SSc patients were having pulmonary hypertension (Table 3). It was seen that pulmonary hypertension is more common in SSc patients than SLE and RA patients.

Table 3- Pulmonary hypertension in 50 patients studied

\begin{tabular}{|l|c|c|c|c|}
\hline PULMONARY HTN & RA & SLE & SSC & TOTAL \\
\hline MILD & 1 & 6 & 2 & 10 \\
\hline MODERATE & 1 & 1 & 0 & 2 \\
\hline SEVERE & 0 & 0 & 2 & 2 \\
\hline NORMAL & 8 & 26 & 3 & 36 \\
\hline TOTAL & 10 & 33 & 7 & 50 \\
\hline
\end{tabular}

SLE- Systemic Lupus Erythematosus; RA- Rheumatoid Arthritis; SSc- Systemic Sclerosis

From radiological point of view (HRCT and Chest $\mathrm{x}$-ray) most common pulmonary disease observed from HRCT findings was interstitial lung disease (38\%) followed by pleural effusion (10\%). However pleural effusion was the major pathology found in Chest X-Ray. 20\% of all RA patients, $36 \%$ of all SLE patients and $72 \%$ of all SSc patients had HRCT findings suggestive of parenchymal lung diseases (ILD). 20\% of RA patients, $6 \%$ of SLE patients and $14 \%$ of all Systemic Sclerosis patients had pleural effusion (both in Chest X ray and HRCT findings). ILD is most common in systemic sclerosis. (Table 4,5) 
Table 4- HRCT findings of the 50 patients studied

\begin{tabular}{|l|c|c|c|c|}
\hline \multicolumn{5}{|c|}{ DISEASE } \\
\hline HRCT FINDINGS & RA & SLE & SSC & TOTAL \\
\hline PLEURAL EFFUSION & 2 & 2 & 1 & 5 \\
\hline $\begin{array}{l}\text { INTERSTITIAL } \\
\text { THICKENING }\end{array}$ & 2 & 12 & 5 & 19 \\
\hline NORMAL & 6 & 19 & 1 & 26 \\
\hline TOTAL & 10 & 33 & 7 & 50 \\
\hline
\end{tabular}

SLE- Systemic Lupus Erythematosus; RA- Rheumatoid Arthritis; SSc- Systemic Sclerosis

Table 5- Chest X-Ray findings of the 50 patients studied

\begin{tabular}{|l|c|c|c|c|}
\hline \multicolumn{5}{|c|}{ DISEASE } \\
\hline CXR FINDINGS & RA & SLE & SSC & TOTAL \\
\hline PLEURAL EFFUSION & 2 & 2 & 1 & 5 \\
\hline PATCHY OPACITY & 1 & 9 & 3 & 13 \\
\hline NORMAL & 7 & 22 & 3 & 32 \\
\hline TOTAL & 10 & 33 & 7 & 50 \\
\hline
\end{tabular}

SLE- Systemic Lupus Erythematosus; RA- Rheumatoid Arthritis; SSc- Systemic Sclerosis

Table 6 denotes the various pulmonary function abnormalities in patients with CTDs, under our study. We found that among all the total patients, $74 \%$ were having restrictive pattern of lung disease, $10 \%$ mixed type of disease and 10\% were obstructive pattern, rest $6 \%$ were normal. Pulmonary function was abnormal in 90\% (30 patients) of all SLE patients (33 patients), 72\% (24 patients) of all SLE patients had restrictive type of lung disease and $10 \%$ were having normal pattern and rest (4 patients) had mixed pattern of lung disease. All the SSC patients showed abnormal pulmonary function; $86 \%$ of them had restrictive pattern of lung disease and $14 \%$ were having mixed pattern in spirometry. $70 \%$ of RA patients were having restrictive pattern whereas $30 \%$ were normal.

Table 6- Pulmonary function abnormalities in 50 patients studied

\begin{tabular}{|c|c|c|c|c|}
\hline \multicolumn{5}{|l|}{ DISEASE } \\
\hline $\begin{array}{l}\text { PATTERN OF } \\
\text { LUNG DISEASE }\end{array}$ & RA & SLE & SSC & TOTAL \\
\hline Restrictive & 7 & 24 & 6 & 37 \\
\hline Mixed & 0 & 4 & 1 & 5 \\
\hline Obstructive & 1 & 2 & 0 & 3 \\
\hline Normal & 2 & 3 & 0 & 5 \\
\hline TOTAL & 10 & 33 & 7 & 50 \\
\hline
\end{tabular}

\section{Discussion}

A majority of the patients in the present study (66\%) had SLE while RA contributed to $20 \%$ and SSc $14 \%$ of the cases. Dry Cough and dyspnoea mainly on exertion were the most common respiratory symptoms. Females are more commonly affected by the diseases than men. In our study female to male ratio was 44:6.

Respiratory tract involvement occurs in majority of patients suffering from SLE. Some patients may have more than a single form of respiratory system involvement during the course of their illness. Pleural involvement (in the form of pleural effusion) is the most common type of respiratory involvement in SLE. Badui et $a l^{[6]}$ previously performed a study on 100 patients of SLE and reported a prevalence of $7 \%$ of pleural effusions in patients with SLE. In another study, performed by Fenlon et al the ${ }^{[7]}$ prevalence of pleural effusion was $9 \%$ as per the HRCT findings. In our present study, pleural effusions were observed in $6 \%$ of the patients with SLE. ILD is reported in patients with SLE, but the result defers in our study with that of reference. In one study, performed by Gross $\mathrm{M}$ et $a l^{[8]}$ this was reported in $10.7 \%$ of the study population, while in another study, ${ }^{[9]}$ it was found to be $13.3 \%$. In this present study, diffuse interstitial pattern was observed in $36 \%$ of the cases (SLE). The ILD in SLE patients presents with diffuse bilateral interstitial thickening, with a lower lobe predominance. Pulmonary function test by spirometry demonstrates restrictive ventilatory defect in majority of SLE patients, although the severity of impairment varies. ${ }^{[10]}$. In our study restrictive pattern is seen as high as upto $72 \%$ in all SLE patients. Restrictive defect occurs due to ILD and pleuritis. The prevalence of SLE associated pulmonary hypertension varies with several studies demonstrating 5 percent to as high as 14 percent $^{[11]}$. In the present study, $18 \%$ had mild pulmonary artery hypertension. Recent studies suggest that mild pulmonary hypertension is much more common in SLE, and is gradually progressive in course of time. 
The most common respiratory involvement in RA are pleural abnormalities and $\operatorname{ILD}^{[12-14]}$, other types are airway involvement, nodular lesions and pulmonary vascular disease. The ILD is the most common manifestation of $\mathrm{RA}^{[15]}$. The reported prevalence of ILD in RA varies from 10 percent to 47 percent $^{[16]}$. In the present study, interstitial pattern consistent with ILD was observed in $20 \%$ of the patients. Ventillatroy abnormalities are common in RA and restrictive ventilation defects suggestive of ILD are reported in $42 \%$ to $60 \%$ of patients $^{[17]}$. In the present study, $70 \%$ of the patients with RA had restrictive ventilatory defect, and this was seen in patients with ILD and pleural effusion. Pleural effusions are observed in approximately $15 \%$ of patients with RA, in a study performed by Shannon JM et al ${ }^{[18]}$.

In our present study, pleural effusions were observed in $20 \%$ of the RA patients. Secondary pulmonary arterial hypertension is common in patients having ILD. In the present study, pulmonary hypertension was observed in $20 \%$ of the patients with RA.

Lung is the most common organ to be involved in Systemic sclerosis and pulmonary complications are the most frequent cause of death in patients with scleroderma. ${ }^{[19]}$ The ILD is the most common lung involvement in scleroderma. About $74 \%$ of the affected patients are found to have interstitial fibrosis at autopsy. ${ }^{[20]}$ In the present study, ILD was observed in $72 \%$ of the scleroderma patients. Pulmonary function tests shows restrictive ventilatory defect in the majority of the cases (86\%) in our study, similar result was found in the study conducted by Sergiacomi G et al. ${ }^{[21]}$ Pulmonary hypertension in patients with scleroderma ranges from 6 percent to 60 percent. In our present study $67 \%$ of all SSc patients were found to have pulmonary hypertension.

\section{Conclusion}

In summary, the pulmonary manifestations are common in various CTDs (included in our study), at some point of time during the course of the disease. Some of these manifestations may remain asymptomatic or manifestations, like interstitial fibrosis can progress gradually resulting in death. So early recognition and introduction of the therapy will help in preventing the morbidity and mortality in such cases.

\section{References}

1. El-Gabalawy H. Common denominators of inflammatory joint diseases. J Rheumatol Supp2005;72:3-6.

2. Good JT Jr, King TE, Antony VB, et al: Lupus pleuritis: clinical features and pleural fluid characteristics with special reference to pleural fluid antinuclear antibodies. Chest 84:714-718, 1983.

3. Matthay RA, Schwarz MI, Petty TL, et al: Pulmonary manifestations of systemic lupus erythematosus: review of twelve cases of acute lupus pneumonitis. Medicine 54:397-409, 1975.

4. Bongartz T, Nannini C, Medina-Velasquez $\mathrm{YF}$, et al: Incidence and mortality of interstitial lung disease in rheumatoid arthritis: a population-based study. Arthritis Rheum 62(6):1583-1591, 2010.

5. Steen VD, Medsger TA: Changes in causes of death in systemic sclerosis, 1972-2002. Ann Rheum Dis 66:940-954, 2007.

6. Badui E, Garcia-Rubi D, Robles E, Jimenez J, Juan L, Deleze $\mathrm{M}$, et al. Cardiovascular manifestations in systemic lupus erythematosus: prospective study of 100 patients. Angiology 1985;36:431-4.

7. Fenlon MM, Doran M, Sant SM, Breatnach E. High resolution chest CT in systemic lupus erythematosus. AJR Am J Roentgenol 1996;166:301-4.

8. Gross M, Esterly JR, Earle RH. Pulmonary alterations in systemic lupus erythematosus. Am Rev Respir Dis 1992; 105:572-4.

9. Huang CT, Hennigar GR, Lyons HA. Pulmonary dysfunction in systemic lupus 
erythematosus. New Engl $J \quad M e d$ 1965;272:288-90.

10. Murin S, Wiedemann HP, Mathay RA. Pulmonary manifestations of systemic lupus erythematosus. Clin Chest Med 1998;19:645-65.

11. Winslow JM, Ossipor MA, Fazio GP, Simonson JH, Redberg RF, Schiller NB, et al. Five year follow up study of the prevalence and progression of pulmonary hypertension in systemic lupus erythematosus. Am Heart J 1995;129:5104.

12. King TE. Connective tissue disease. In: Schwarz MI, King TE, editors. Interstitial Lung Disease. 3rd edition. Hamilton, Ontario: BC Decker Inc. 1998;pp451-505.

13. Light R. Pleural disease due to collagen vascular disease. In: Pleural Diseases. 2nd edition. Philadelphia: Lea and Febiger. 1990;pp205-15.

14. Shiel WO, Prete PE. Pleuro-pulmonary manifestations of rheumatoid arthritis. Sem Arthritis Rheum 1982;58:187-9.

15. Walker WC, Wrightt V. Pulmonary lesions and rheumatoid arthritis. Medicine 1982;58:187-9.

16. Gabbay E, Tarala R, Will R, Carrol G, Adler B, Cameron D, et al. Interstitial lung disease in recent onset rheumatoid arthritis. Am J Respir Crit Care Med 1997;156:528-35

17. Fujii M, Adachi S, Shimizu T. Interstitial lung disease in rheumatoid arthritis: assessment with high resolution computed tomography. J Thorac Imag 1993;8:54-62.

18. Shannon JM, Gale ME. Noncardiac manifestations of rheumatoid arthritis in the thorax. J Thorac Imag 1992;7: 19-29.
19. Minai OA, Dweik RA, Arroliga AC. Manifestations of scleroderma pulmonary diseases. Clin Chest Med 1998; 19:713-31.

20. Wiedemamn HP, Matthay RA. Pulmonary manifestations of collagen vascular diseases. Clin Chest Med 1989;10:677721.

21. Sergiacomi G,De Nardo D, Capria A, Manenti G,Fabiano S,Borzi M,De Sanctis G,Konda D,Sperandio M,Schillaci O,Masala S,Simonetti G,Fontana L. Noninvasive diagnostic and functional evaluation of cardiac and pulmonary involvement in systemic sclerosis. In Vivo. 2004 Mar-Apr;18(2):229-35. 